\title{
IMAGINARIZAÇÃO DO SIGNIFICANTE E FORCLUSÃO DA CULPABILIDADE
}

\author{
Luiz Carlos Santuário*
}

\begin{abstract}
SÍNTESE - O texto procura identificar, a partir da psicanálise de Lacan, de que forma, em função do indevido privilégio egóico dado pelo sujeito falante ao Registro do Imaginário, a percepção e compreensão da insistência do significante permanece restrita a este registro, impossibilitando-lhe uma compreensão mais ampla, correspondente à inscrição do significante no Registro do Simbólico, co-extensivo ao ethos do sujeito humano. Isto implicaria, em certo sentido, na forclusão da culpabilidade, ou, pelo menos, num certo conforto imaginário da ek-sistência do sujeito.
\end{abstract}

PALAVRAS-CHAVE - psicanálise, filosofia, Lacan, Heidegger, simbólico, culpabilidade.
ABSTRACT - This paper aims to identifiy how from Lacan's psychoanalysis, the undue egoic privilege given to the imaginary registry, makes the subject perceive and comprehend the inscription of the signifier attached chiefly to this registry, not enabling him to have a wider comprehension, corresponding to the inscription of the signifier in the symbolic registry, related to the ethos of the human being. This would imply, in a certain way, the forclosure of the culpability, or, at least, in a certain imaginary comfort regarding the existence of the subject.

KEY WORDS - psychoanalysis, philosophy, Lacan, Heidegger, symbolic, culpability.

De que forma poderíamos proceder corretamente à delimitação do território conceitual onde seriam passiveis de serem verificadas as teses apresentadas pelo discurso da psicanálise? A possivel resposta a esta questão pressupõe a compreensão de que o campo conceitual da psicanálise é um território produzido a partir de uma gramática própria e especifica, solidária e co-extensiva aos fenômenos que procura reconstruir e descrever. Desta forma, o estabelecimento deste território conceitual, onde pudesse ser verificada a procedência e amplitude dos termos ali utilizados e a produção de uma ferramenta conceitual aí aportada deve ter em conta, inicialmente, esta especificidade de gênese.

Tomemos, como outro exemplo desta propedêutica, o território do discurso filosófico. A filosofia, como todo campo de saber, institui-se a partir de uma certa gramática, que lhe é específica. Esta gramática deve ser não apenas compreendida por todo aquele que se aproxima deste campo do saber, como toda crítica e

* Professor da Universidade de Caxias do Sul (UCS) e doutorando em Filosofia na PUCRS.

\begin{tabular}{|l|l|l|l|l|l|}
\hline VERITAS & Porto Alegre & v. 43 & $\mathrm{n}^{\mathrm{0}} 1$ & Março 1998 & p. 91-96 \\
\hline
\end{tabular}


reconstrução categorial deve ser feita em função do modo de operação e funcionamento daquela gramática. A decifração do sentido, da forma de apresentação da linguagem filosófica somente pode ser compreendido em função da compreensão da gramática a partir da qual ela, linguagem filosófica, foi instituída, que não é a da linguagem civil da atitude ingênua. A filosofia pode ser compreendida utilizando-se metaforicamente as categorias da gramática computacional, como uma operação de digitalização (re-construção digital) do sentido. Ou, dito de outro modo, o mundo analógico do realismo ingênuo é re-construído digitalmente pela atividade filosófica.

Como advertência e sinalização deste empreendimento hermenêutico de reconstrução e compreensão, o professor Stein, em seu texto Metalinguagem e compreensão nas ciências humanas comenta: "A atividade de compreender a dimensão da sistematicidade do texto se realizará como uma espécie de reconstrução em busca de uma esfera lógico-lingüística em que autor e intérprete cheguem a mover-se no mesmo sistema de referências e antecipem as condições de um entendimento sobre a questão de que trata o discurso cristalizado."1

A possibilidade de reconhecer o território no qual o sujeito falante se movimenta e a capacidade de movimentar-se hermeneuticamente no registro do discurso instituído pela psicanálise supõe, inicialmente, a possibilidade de compreender a psicanálise enquanto empreendimento de re-construção. Desta forma, a abordagem da problemática filosófica apresentada pelos textos da psicanálise, procurando compreender de que modo se articulam, como são propostos, com que legitimidade buscam apresentar-se deve ser solidária a uma abordagem interna da conceitografia trazida pela psicanálise, procurando compreender a amplitude dos termos, seu alcance e eficácia de atuação, ou seja, necessitaríamos produzir uma hermenêutica co-extensiva à dialética interna de sua terminologia.

A psicanálise de Lacan construiu a noção de Registros (Imaginário, Simbólico, Real) como dispositivos metodológicos que possibilitassem a compreensão daquilo que suporta a existência ou insistência da manutenção da vida (ou da morte) de um sujeito. Assim, aquilo que a psicanálise designa como Registro do Imaginário, tem uma primeira referência ao regime ou registro do assujeitamento da criança à mãe (elemento protético suturador da neotenia do infans). Esta, atuando aí como elemento vetor da possibilidade de construção, por parte do sujeito, da primeira idéia-de-si-mesmo.

Entretanto, o sujeito, nos diz a psicanálise lacaniana, é fundado, ou está ancorado, em dois lugares. Existe, imaginariamente, junto ao mundo oftálmico dos objetos empiricos e ek-siste, aislado, ou exilado (de sua imaginária completude) no Registro do Simbólico (cujo acesso é garantido por uma metáfora fundadora, referida por Lacan como nome-do-pai, ou terceiro, do qual não há meta-discurso).

A vinda ou presença do significante utilizado pelo sujeito falante divide assim o objeto empírico que, agora, ocupa igualmente dois campos: campo do objetoobjeto, no registro do imaginário (fundação da idéia-de-si mesmo), re-incorporável e re-atualizável pela operação de fagocitose do olhar (nivel da sedução imaginária)

1 STEIN, Enildo. Instauração do sentido. Porto Alegre: Movimento, 1977, p. 88. 
e, de outro lado, campo do objeto-palavra, no registro simbólico, onde o objetoreferente é imaginariamente re-incorporado pela nomeação ou aposição exterior do signo ao objeto. O Imaginário funciona assim enquanto registro de manutenção social do sujeito. Opera como regime e lógica autista de colação do sujeito aos objetos do universo empírico. É o território da subjetividade, da individualidade e da particularidade de cada sujeito falante. O Registro do Imaginário é co-extensivo ao registro fáctico, enquanto o Simbólico é co-extensivo ao registro do contrafáctico.

Existiria assim uma certa incapacidade, devida à eficácia da má fé prévia do Imaginário em incluir o significante e concebê-lo, desde-sempre, como existindo a partir do campo do simbólico. O Imaginário funciona como registro onde se reconhece o Ego. O Simbólico como registro onde o significante e suas leis de articulação constituem o campo específico do humano-ser, enquanto sujeito falante.

$\mathrm{O}$ ato que funda ou institui onticamente, isto é, narcisicamente o ente fal(t)ante é o de ter de ser instado a providenciar, de modo imediato, uma resposta ao que aparece na cena pública como visível, identificado apressadamente como realidade. A linguagem, aí, se cola ou adere àquilo que o olhar, narcisicamente, olha. Neste caso, a realidade entra pelos olhos, não havendo nenhum ato filosófico, hermenêutico, interpretativo, nenhuma possibilidade de entendimento dos eventos intramundanos para além da singela empiria. Esta "des-coincidência" dos registros e da fixação imaginária - e narcísica - do desejo na cadeia significante, institui o privilégio do oftalmológico, que devolve ao sujeito sua forma linda e completa, porém, imaginária. No Registro do Imaginário há uma complementaridade entre as operações de conhecer, re-conhecer e re-conhecer-se.

A imagem, neste registro, funciona para o sujeito falante como corespondente ou co-incidente ponto por ponto ${ }^{2}$ da noção-idéia-de-si-mesmo, pois re-atualiza a completude do campo onde imaginariamente habita o sujeito falante.

A psicanálise lacaniana institui assim um campo conceitual novo ao dizer que a inteligibilidade do fenômeno não é dada pela presença do objeto empírico, mas pela antecipação (da eficácia) do signo. O significante, para a psicanálise é semioticamente carregado e, contrariamente ao postulado pela lingüística não é (diretamente) suporte de significado, posto que o modo próprio de eficácia e funcionamento do significante dá-se em função de estar conectado, primordialmente, a outro significante, em cadeia, (eslabón, chain) e não a um significado (imediato) exterior à cadeia. Desta forma, a opacidade do mundo empírico (qua mundo oftálmico dos objetos) apresentar-se-ia como necessária, para que o significante possa aí intervir fundando a presença egóica e imaginária do sujeito, que viria ali para fundar, posteriormente, geocentricamente e cartesianamente o mundo.

Aquilo que Lacan articula como registro do Simbólico tem uma primeira referência à operação da metáfora paterna que atua como garantia do acesso do sujeito falante a este Registro, territóno no qual a palavra atua como signo e, assim, atualiza e presentifica a ausência do objeto originariamente perdido pelo sujeito.

2 MULLER, John P. Beyond the psychoanalitic dyad (Freud/Lacan/Peirce). London: Routledge, 1996, p. 94. 
Ou, na descrição que faz Joel Dor: "O simbolo da linguagem tem, portanto, por vocação exprimir a perenidade do objeto fundamental do desejo numa designação que se efetua com o desconhecimento do sujeito. Isto equivale a dizer, com Lacan, que a linguagem permite 'eternizar sua expressão', socializando-a no registro simbólico da comunicação intersubjetiva."”

O Registro do Simbólico, atuando como campo do a priori e constituidor de sentido para o sujeito, possui um caráter de existência ou insistência contrafática, contrariamente ao Registro do Imaginário que, simplesmente institui o regime da imediata facticidade. No Registro do Simbólico, a palavra opera como ancoradouro da identidade simbólica e estrutural do sujeito falante e funciona como elemento de contra-senha do re-conhecimento simbólico do sujeito no seio cultural e histórico. O Simbólico possui esta característica de convencionalidade na medida em que a língua advém como estando estruturada por um Autre, operando como uma lógica que antecede o sujeito.

A palavra do sujeito falante, inscrita desde sempre no territónio do Simbólico institui um dos eixos de manutenção da ek-sistência do sujeito. O outro eixo sendo o do olhar, opera ao nível da fagocitose de objetos empiricos. Esta ancoragem anfíbia do animal humano no eixo da palavra (simbólico) de um lado, e do olhar (imaginário) de outro, possibilita, por exemplo, ao semioticista norte-americano Thomas Sebeok falar do humano como ser bio-semiótico. ${ }^{4}$ A partir disto, a noção de temporalidade talvez devesse ser pensada como solidária, simultaneamente a dois eixos ou dois momentos de sua atualização para o sujeito:

a) Um eixo, enquanto regido pelas operações da metonímia. Universo aberto, da temporalidade empírica, composto de uma multiplicidade de objetos e do sujeito qua ego. Eixo horizontal, compreensão bi-dimensional do espaço e compreensão do tempo enquanto singela cronologia.

b) Outro eixo da temporalidade, co-extensivo às operações da metáfora fundadora e regido pelas leis que presidem à articulação da cadeia significante.

O discurso trazido pela psicanálise nos situa, portanto, desde sempre, no território daquilo que a filosofia apreende com o conceito de aporia, pois a psicanálise apresenta o Registro do Simbólico como pré-existente em relação às pretensas formulações de caráter conteudístico e teleológico por parte do sujeito. Assim, a introdução e utilização da lingüisteria, por Lacan, pode ser compreendida como operador metodológico, garantidor da aufhebung da aporia surgida ou trazida pela concepção de que o significante é opaco (isto é, não remissivel, num primeiro tempo, a um universo de objetos empíricos) e anterior ao sujeito.

Em seu recente livro Anamnese, o professor Stein assim compreende a noção de lingüisteria: "A expressão lingüisterie é mais do que um jogo de palavras, ela representa a expulsão das leis lingüisticas, recém-introduzidas na psicanálise, e a

3 DOR, Jöel. Introdução à leitura de Lacan (o inconsciente estruturado como linguagem). Porto Alegre: Artes Médicas, 1989, p. 93.

4 MULLER, John P. Beyond the psychoanalitic dyad (Freud/Lacan/Peirce). London: Routledge, 1996, p. 37. 
afirmação da possibilidade de formação de estrutura do inconsciente, através de um discurso gerado pelo próprio Lacan." 5

Compreendendo assim a noção de lingüisteria como gramática solidária à extração do modus imperialista da primazia do significante, nada nos autoriza à apressada conexão dos campos conceituais estabelecidos pela psicanálise e por Heidegger, por exemplo, quando ambos concluem que a condição humana não tem Devemos estar advertidos que o resultado obtido em cada um é fruto e resultado da utilização de ferramentas que operam em registros e espaços distintos de reconstrução e interpretação. Nada autoriza, portanto, a conexão dos resultados se os métodos ou caminhos são distintos, na gênese. A analítica existencial heideggeriana não poderia, portanto, ter função de replacement, ou substituição, da conceitografia lacaniana.

$\mathrm{Na}$ obra citada anteriormente, o professor Stein comenta sobre "o poder forclusivo da filosofia de Heidegger e a fé mágica no pensamento" e sobre a forclusão simbólica em Heidegger. "O filósofo sofre, por isso, com o imaginário que the causa o "mal estar na cultura". Sua obra irá retratar essa luta contra os limites do simbólico, por isso ela não será jamais, um pensamento voltado para o estabelecido e a ação a ser orientada nele."6

E, ainda, mais adiante: "Esta combinação entre o projeto filosófico de destruição e a incorporação da destruição como elemento de crítica à realidade histórica, abriu na vida e na obra de Heidegger um espaço extremamente perigoso. Talvez 0 elemento fundamental desse espaço tenha-se tornado uma certa incapacidade em reconhecer, no simbólico, um limite fundamental, estabelecido pelas leis, pelas regras, pelas instituições e pelo conhecimento científico em geral, dando, por meio da interpretação filosófica, um extremo poder ao imaginário."7

Assim, enquanto por um lado Marx nos descreve uma alienação de caráter objetivo, passivel de ser desatada e Freud nos descreve uma alienação da condição humana que seria da ordem do constitutivo, de um assujeitamento cultural porém não desatável socialmente, Lacan nos aponta para este campo do absolutamente paradoxal e aporético que acompanha, desde sempre, o gênero humano, habitante do Simbólico.

Desta forma, contrariamente às operações singelamente ônticas de "imaginarização do significante", para além da mera circunscrição do significante ao registro do circuito egóico é necessário compreendê-lo como estando inscrito num regime, num Registro mais amplo, num território de maior amplitude que 0 da mera circulação representada pelas identificações imaginárias do pequeno eu, representado iconicamente pelo sujeito cartesiano.

Para além do territónio do cartesianismo opera, se quisermos falar com Lacan, ${ }^{8}$ o território ou Registro do Simbólico e, se quisermos falar com $\mathrm{Apel}^{9}$, o território do

\footnotetext{
STEIN, Ernildo. Anamnese. Porto Alegre: EDIPUCRS, 1997, p. 31.

STEIN, idem, p. 128.

STEIN, idem, p. 130.

LACAN, Jacques. Écrits. Paris: Seuil, 1966.

9 APEL, Karl-Otto. La transformación de la filosofia. Madrid: Taurus, 1985. v. 1, passim. (Tradução de Adela Cortina, Joaquin Chamorro y Jesús Conill).
} 
contra-fático, da comunidade ilimitada de comunicação como território garantidor da intelegibilidade semiótica do universo aberto pelo significante. Talvez se pudesse falar então de uma forclusão da culpabilidade, ou de um certo conforto ilusório garantido por esta existência imaginária, produto de um certo mimetismo filosófico, aquém da incorporação de todas as conseqüências advindas deste outro territónio semiótico.

\section{Referências bỉbliográficas}

APEL, Karl-Otto. La transformación de la filosofia. Madrid: Taurus, 1985. v. 1, passim.

DOR, Jöel. Introdução à leitura de Lacan (o inconsciente estruturado como linguagem). Porto Alegre:

Artes Médicas, 1989, p. 93.

LACAN, Jacques. Écrits. Paris: Seuil, 1966, p. 11.

MULLER, John P. Beyond the Psychoanalitic Dyad (Freud/Lacan/Peirce). London: Routledge, 1996, p. 37.

STEIN, Emildo. Instauração do sentido. Porto Alegre: Movimento, 1977, p. 88.

Anamnese. Porto Alegre: EDIPUCRS, 1997, p. 31. 